\title{
Video games as the digital entertainment platform during the COVID-19 pandemic
}

\author{
A.M. Maheswara* \& V. Wibowo \\ University of Indonesia, Jakarta, Indonesia
}

\begin{abstract}
COVID-19 has had a huge impact on the world community - starting from school children, teachers, or employees. Governments in some countries implement a lockdown system that forces people to work and have activities at home. This was an important momentum for video game developers to contribute more to society. This research focuses on the European video game industry, considering that Europe has a sizable video game industry. This study uses a sociocultural approach with qualitative methods and literature study. Through this research, it is hoped that it will open up new perspectives and knowledge regarding the contribution of video games in society. Based on the results of this study, shows that video games can be a source of alternative entertainment and educational tools to make it easier for people to carry out their daily activities even though they are at home during the pandemic.
\end{abstract}

Keywords: COVID-19, pandemic, video game industry, socio-cultural, Europe

\section{INTRODUCTION}

The existence of video games departs from the postmodernism movement. The entry of the postmodernism era caused many things to experience a shift to be more flexible, non-linear, and diverse. The definition of postmodernism itself is said differently by many postmodernists. According to Daniel Bell (1992), postmodernism is an era of post-industrial society that has switched to information technology systems (Bell, 1992). In other words, postmodernism can be said to be part of the current technological progress, resulting in the emergence of various kinds of innovations in terms of technology and the production of goods. The influence of postmodernism shifted some aspects of the use of technology to works of art. Artworks that were initially known to only involve fine art, painting, music, theater or film, are now more developed with the entry of the video game industry into the category of a work of art. Chris Melissinos as an influential figure in the field of technology said in a Time magazine interview (2015) that the video game industry will prove to be one of the most important art mediums that mankind has ever produced (Melissinos, 2015).

The main objective of this research is to find out how the video game industry in Europe continues to run during the COVID-19 pandemic and how they provide alternative entertainment for the wider community, namely through a video game. With this research, it is hoped that it can provide new insights, knowledge, and perspectives for the community on the video game industry, considering that there are still many people who only see the negative impact of a video game.

\section{METHODS}

This study uses qualitative research methods and the approach used in this study is a literature study approach. The process of data collection in the preparation of this research includes: First, the process of data collection is collected through books, scientific papers, or electronic media with

${ }^{*}$ Corresponding Author 
discussions that discuss the global and European video game industry. Second, the authors also find out previous research that discusses the video game industry globally, especially in Europe. Third, processing the data that has been collected and concluding it into a simple analysis.

\section{RESULTS AND DISCUSSION}

Technological advances have made video games available to the public at large and the industry has become one of the fastest-growing segments in the global media and entertainment market. Video games were started in the 1950s in the United States in the context of research to create a new, more modern recreation platform. Then, in the 1970s the development of video games accelerated rapidly among young people until the 1980s (Wolf, 2012). At that time, video games were still considered insufficiently connected to the arts. However, over time, video games not only contained elements of entertainment but also added an artistic element to them. The growing video game industry in the United States and Japan led countries in Europe to form their industries in the 1980s and 1990s. Since then, the video game industry in Europe has grown and is able to compete in the video game industry market with the United States and Japan.

Among music, film, and video game industries, the industry that has benefited the most is the video game industry. The Entertainment Retailers Association (ERA) said the market value of video games rose to 3.864 billion Euros, more than double its value in 2007. This makes the video game market bigger than the combined film and music markets for the first time (Parson, 2019). Moreover, when the COVID-19 pandemic is occurring, the video game industry around the world is taking advantage of this pandemic to bridge society through video games so they can still get entertainment without having to leave their homes.

During a pandemic like this, many school children are forced to learn from their homes. However, many schools use video games as a medium for providing information regarding all activities at school. One of the schools in England, Wisbech School, uses the game Minecraft as a tool that allows students to get important information in their school. This project has been initiated by the Wisbech School art teacher, John Birch, since 2018 through the Minecraft Education Edition. For Birch, in these conditions, the use of Minecraft is very important for students to get to know their school and school staff more closely. Many parents also responded to this project with positive responses, because their children can still come to school and interact with each other through the virtual school formed by Birch (Leishman, 2020). Minecraft itself is a video game created by a British video game developer, 4J Studios, and already has more than 400 million players from around the world.

Apart from being a medium for school information, Minecraft is also used by academics in several countries to hold graduations virtually. It is recorded that there are more than twenty universities around the world that have conducted virtual graduation through Minecraft, such as Stanford University, Singapore University of Technology and Design, to MIT (Minecraft, 2020). Recently, one of the universities in Indonesia, such as the Sepuluh Nopember Institute of Technology (ITS), used Minecraft to hold a graduation ceremony at the university. For teachers, students, and families, the Minecraft world is a fun medium to take a real Minecraft Ian (Minecraft resident) graduation.

Although they have been popular since before the pandemic, now video games are becoming more and more popular. NPD Group noted that until 2020, there was a $23 \%$ increase in sales of video game consoles in the United States, while sales of iPhone mobile games in Europe in July 2020 increased by $20 \%$. The Nielsen survey said that up to June $2020,41 \%$ of game players in France admitted to playing games more often due to the pandemic (Quartz, 2020). This increase in the number of sales certainly confirms that more and more people are spending their time during the pandemic playing video games. Here, people turn to video games as a means to entertain themselves, as well as to pass the time during a pandemic, especially during a lockdown. Health experts have even allowed playing video games as a stress reliever during a pandemic.

At times like this, video games help people to solve their social needs problems. It is also an aid to improving mental health by connecting people and communities, thereby saving them from anxiety and depression. In one study it was found that the regimen prescribed for playing video 
games significantly reduced symptoms of clinical depression as measured by the Patient Health Questionnaire 9 (PHQ-9) (Russuniello, 2013). It was also found in other studies that research participants who played video games showed improvements in mood and liver function (Anguera, et al, 2017). Socialization through playing games is a good thing for now. Game developers are now focused on increasing engagement between users, which will also increase in-game microtransactions. Changing consumer perceptions of video games which are now valued as a form of learning activity and a useful way of spending leisure time is a different view, seeing video games as artistic expressions and a form of modern entertainment, which in turn will make the market of this field continue to grow. From this arose a new trend called "Gamification of Education" because of the educational value offered by video games, where games are used as a valuable and high-tech teaching tool to convey 21 st-century skills such as creative thinking, problem-solving, and collaboration (Globe, 2020).

It can be seen that video games are contributing to society during the COVID-19 pandemic and creating good impacts, including improving mental health or reducing stress, increasing innovation in the video game industry, and assisting in the implementation of teaching and learning activities. With the limited number of people to move and do something, the number of events that have been canceled or postponed until an undetermined time, the closure of entertainment centers in various places, and the lack of entertainment that can be obtained, video games have become new digital media for the public to move in their mind, socializing, teaching and learning, expression and imagination

\section{CONCLUSIONS}

Video games were originally considered entertainment. However, the rapid development of technology has made video games turn into an important thing to bring about change, even solutions to some social problems. Looking at the creative process in the video game industry can make us understand that video games are quite complex in their development. During a pandemic, the video game industry can be said to be one of the industries that have succeeded in becoming digital entertainment for the community. In addition, video games are also used as educational media in several countries. This research can open up new perspectives on the use of video games in everyday life. The author argues that in the future, it is possible that video games can be used as a new social media that can connect life between people around the world.

\section{REFERENCES}

Anguera, J.A. et al. 2017. Improving late life depression and cognitive control through the use of therapeutic video game Technology: A proof-of-concept randomized. Depression and Anxiety 34(6): 508-517.

Bell, D. 1992. The End of Ideology: On the Exhaustion of Political Ideas in the Fifties. New York: Free Press.

Globe Newswire. 2020. Global video games industry. Retrieved from: https://www.globenewswire.com/newsrelease/2020/09/09/2090627/0/en/Global-Video-Games-Industry.html

Leishman, F. 2020. Thomas clarkson academy: Wisbech school transformed in minecraft so new students can go on a 'tour'. Retrieved from: https://www.cambridge-news.co.uk/news/local-news/thomas-clarksonacademy-wisbech-open-19051121.

Melissinos, C. 2015. Video games are one of the most important art forms in history. Retrieved: https:// time.com/collection-post/4038820/chris-melissinos-are-video-games-art/.

Minecraft Education. 2020. Students around the world hold graduations in minecraft - and now you can too! Retrieved: https://education.minecraft.net/blog/students-around-the-world-hold-graduations-in-minecraftand-now-you-can-too.

Parsons, J. 2019. Video Games Are Now Bigger Than Music and Movies Combined. Retrieved: https:// metro.co.uk/2019/01/03/video-games-now-popular-music-movies-combined-8304980/

Quartz. (2020). Everyone is playing video games during the pandemic. 2020. Retrieved: https://qz.com/ 1904276/everyone-is-playing-video-games-during-the-pandemic/.

Wolf, M.J. P. (Ed). 2012. Encyclopedia of Video Games: The Culture, Technology, and Art of Gaming. California: Greenwood. 